\title{
First molecular cytogenetic characterisation of tracheal squamous cell carcinoma cell line KLN 205
}

\author{
Shaymaa Azawi ${ }^{1}$, Thomas Liehr ${ }^{1}$, Martina Rincic ${ }^{2}$ \\ ${ }^{1}$ Institute of Human Genetics, Jena University Hospital, Friedrich Schiller University, Jena 07747, Germany. \\ ${ }^{2}$ Croatian Institute for Brain Research, School of Medicine University of Zagreb, Zagreb 10000, Croatia.
}

Correspondence to: Dr. Thomas Liehr, Institute of Human Genetics, Jena University Hospital, Friedrich Schiller University, Am Klinikum 1, Jena 07747, Germany. E-mail: Thomas.Liehr@med.uni-jena.de

How to cite this article: Azawi S, Liehr T, Rincic M. First molecular cytogenetic characterisation of tracheal squamous cell carcinoma cell line KLN 205. J Cancer Metastasis Treat 2021;7:38. https://dx.doi.org/10.20517/2394-4722.2021.59

Received: 10 Mar 2021 First Decision: 7 May 2021 Revised: 19 May 2021 Accepted: 2 Jun 2021 First online: 7 Jul 2021

Academic Editor: Lucio Miele Copy Editor: Xi-Jun Chen Production Editor: Xi-Jun Chen

\begin{abstract}
Aim: Murine tumour cell lines have been used in thousands of studies. Strikingly, it is rather the rule than exception for most of them that not much is known about their genetic characteristics. The squamous cell carcinoma (SCC) cell line KLN 205 is such an example. KLN 205 cells have not been studied yet for karyotype or acquired copy number variations ( $C N V s$ ), but they have been used as models for (metastatic) lung cancer, lung-SCC, non-small cell lung cancer, tongue cancer and subcutaneous SCC. Here, it was characterised cytogenomically for the first time.
\end{abstract}

Methods: The cell line KLN 205 was characterised comprehensively by molecular cytogenetics using multicolour banding as well as molecular karyotyping. Based on these results, a map of the imbalances and breakpoints determined in the murine genome was translated to the human genome.

Results: Here, it could be shown that this $>40$-year-old cell line has a stable, approximately tetraploid karyotype comprising 77-82 chromosomes. However, there are few structural chromosomal aberrations: only six derivatives involving chromosomes 2, 3, 5, 9, 10 and/or 19 could be found. According to the literature, SCCs derived from different human tissues, as well as lung SCC and non-small cell lung cancer, display overall similar CNV patterns.

Conclusion: Thus, according to the genetic profile found here, KLN 205 can be applied as a general model for human SCC; it is also suited as a model for lung cancer in general. Further molecular genetic characterisation of KLN 205 cell line may find more lung- and/or SCC-specific alterations. 
Keywords: Lung cancer, squamous cell carcinoma (SCC), murine cell line KLN 205, murine multicolour banding (mcb), array comparative genomic hybridisation $(\mathrm{aCGH})$

\section{INTRODUCTION}

Among the leading adverse forms of acquired malignant diseases is human lung cancer representing 17\% of new cancer diagnoses worldwide. About 30\% of lung-associated cancers are of squamous cell carcinoma (SCC) type ${ }^{[1]}$, and it has been shown that $80 \%-90 \%$ of lung SCCs (L-SCCs) are associated with tobacco consumption, i.e., smoking ${ }^{[1,2]}$. Being a long-standing clinical problem, there are numerous therapeutic options at hand, such as carboplatin- or cisplatin-based cytotoxic chemotherapy, EGFR targeting therapy (e.g., by erlotinibin or cetuximab), anti-angiogenesis treatment by ramucirumab or approaches targeting the immune system with specific inhibitors, e.g., ipilimumab or nivolumab ${ }^{[1]}$. However, not all L-SCC patients can be treated optimally using the currently available options, thus research on, e.g., how to access the $\mathrm{FGFR}^{[3]}$, IGF ${ }^{[4]}$ or $\mathrm{PI} 3 \mathrm{~K}-\mathrm{Akt} / \mathrm{mTOR}$ pathways ${ }^{[5]}$, is ongoing.

Murine cancer cell lines are well established models to perform such studies ${ }^{[3-5]}$. However, most of these murine cancer cell lines have never been (cyto)genetically characterised in detail, irrespective of how often they have already been used in research ${ }^{[6,7]}$. This is because murine chromosomes are hard to distinguish in banding cytogenetics ${ }^{[7]}$.

Thus, the murine cell line KLN 205 (also referred to as KLN205 or KLN-205), being derived from a chemically induced tracheal SCC in $1978^{[8]}$, has also never been characterised using cytogenetics, molecular cytogenetics or molecular karyotyping, even though it has been applied in almost 100 studies. Only the modal chromosome number was determined as being between 73 and $76^{[0]}$. The cell line was induced in the lung of a male $D B A / 2$ mouse by repeated intra-tracheal injections of 3-methylcholanthrene. Then, the tissue was serially passaged in $D B A / 2$ mice intramuscularly, and the 9th and 10th transplant generations were further used as "Nettenheim carcinoma" ${ }^{[10]}$, known to be composed of heterogeneous cell populations ${ }^{[0]}$. Nettenheim carcinoma has been classified as tracheal SCC, as well as been called lung carcinoma, from which the cell line KLN 205 was established by serial sub-cultivation and subcloning ${ }^{[10]}$. Interestingly, the American Type Culture Collection provides the cell line as "forming metastatic lesions in lungs after inoculation into mice" and "SCC cell line" ${ }^{[1]}$. Overall, there seems to be some confusion regarding for which human tumour KLN 205 cells can be used as models. Accordingly, the KLN 205 cell line has been used in studies considering, for example, the following types of cancer:

$\cdot \mathrm{SCC}^{[12-14]}$

- Lung cancer ${ }^{[15-22]}$

- Non-small cell lung cancer ${ }^{[23]}$

$\cdot \operatorname{L}-S C C^{[24,25]}$

- Lung-metastatic tumour cells ${ }^{[26]}$

- Tongue cancer ${ }^{[27]}$ 


\section{- Subcutaneous SCC $[28]$}

It was shown previously that a comprehensive molecular cytogenetic characterisation of murine tumour cell lines can define the cancer subtype to which they belong because the cytogenomic profile of chromosomal imbalances is typically specific to a certain tumour type ${ }^{[6]}$.

Thus, the karyotype, a comprehensive map of chromosomal imbalances, and an in silico translation of these results to the human genome were performed here for the KLN 205 cell line to possibly determine to which human cancer type it is most similar.

\section{METHODS}

\section{Cell line}

The murine KLN 205 cell line (American Type Culture Collection, ATCC CRL-1453 $3^{\text {tw; }}$; Wesel Germany) was grown adherently according to the recommendations of the provider. The cells were cytogenetically worked $\mathrm{up}^{[28]}$ and the whole genomic DNA was extracted from the same passage of cells ${ }^{[29]}$. Molecular cytogenetic and molecular karyotyping [array comparative genomic hybridisation (aCGH)] analyses were done as outlined below.

The KLN 205 cell line was specifically purchased for this study from ATCC. The provider guaranteed the identity of the cell line.

\section{Molecular cytogenetics and karyotyping}

Fluorescence in situ hybridisation (FISH) was performed as previously described ${ }^{[29]}$ using whole chromosome paints ("SkyPaintTM DNA Kit M-10 for Mouse Chromosomes", Applied Spectral Imaging, Edingen-Neckarhausen, Germany) for multicolour-FISH (mFISH) and murine chromosome-specific multicolour banding $(\mathrm{mcb})$ probe mixes for FISH-banding ${ }^{[29]}$. At least 30 metaphases were analysed for each probe set Zeiss Axioplan microscopy, equipped with ISIS software (MetaSystems, Altlussheim, Germany). aCGH was done according to standard procedures by "SurePrint G3 Mouse CGH Microarray, 4×180K" (Agilent Technologies) ${ }^{[29]}$.

\section{Data analyses}

Imbalances and breakpoints of KLN 205 were determined according to mcb and aCGH data and aligned to human homologous regions using Ensembl and the UCSC Genome Browser, as previously described ${ }^{[29]}$. The obtained data were compared to the known genetic changes in human cancers ${ }^{[30-32]}$.

\section{RESULTS}

\section{FISH and aCGH}

The approximately tetraploid cell line KLN 205 had a relatively stable karyotype, falling into four well defined clones with minor but stable differences: Clone 1 (43.3\%) [Figure 1], 77-82,XXYYYY,$2, \operatorname{del}(3)(\mathrm{A} 3 \mathrm{D}), \operatorname{der}(3)(\mathrm{A} 1 \rightarrow \mathrm{A} 3:: \mathrm{D} \rightarrow \mathrm{G} 3:),-4,+\operatorname{del}(5)(\mathrm{C} 3),-7,-8, \operatorname{der}(9) \mathrm{t}(9 ; 10)(\mathrm{A} 5 ; \mathrm{A} 1),-$ 13, der(14)t(2;14)(A2;A1),+15,-17, $\operatorname{del}(19)(\mathrm{D})$; Clone 2 (20\%), same as Clone 1, but $+\operatorname{del}(5)(\mathrm{C} 3)$ instead of +5 and four chromosome 12 instead of three; Clone 3 (13.4\%), same as Clone 2 but four chromosome 2; and Clone 4 (13.4\%), same as Clone 2 but four chromosome 2, no $\operatorname{der}(9) \mathrm{t}(9 ; 10)(\mathrm{A} 5 ; \mathrm{A} 1)$.

Overall, the FISH results are in agreement with those of the aCGH analysis, as summarised in Figure $2 \mathrm{~A}$. An in silico translation of those results to the human genome (only imbalances larger than 3.5 megabase pairs were included in the evaluation) identified the corresponding homologous region in the human genome 


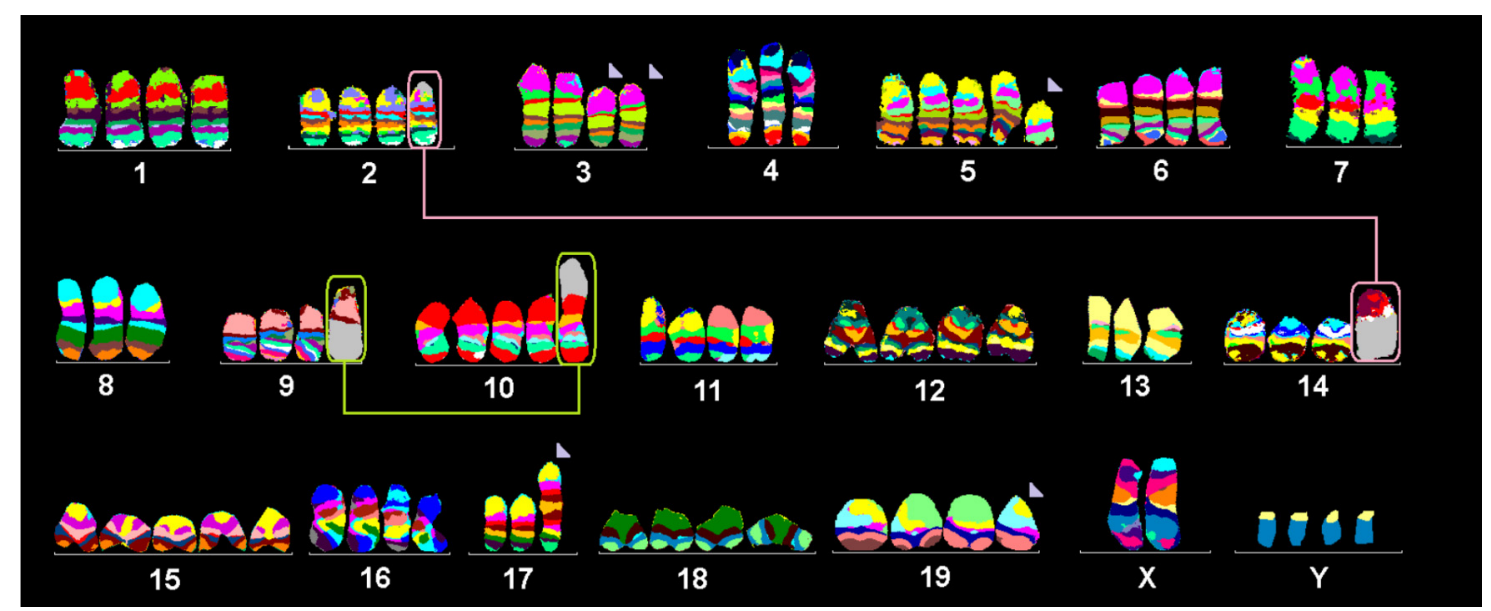

Figure 1. Murine multicolour banding (mcb) was applied on chromosomes of the KLN 205 cell line. This figure depicts the summary of 20 chromosome-specific FISH experiments as typical pseudo-colour banding. Derivative chromosomes consisting of different chromosomes are highlighted by frames and shown twice in this summarising karyogram.

[Figure 2B]. The genomic details are presented in Supplementary Table 1. The aCGH results for murine Ychromosome are not informative.

\section{Comparison with literature}

The corresponding translated homologous CNV regions of the KLN 205 cell line [Figure 2B] were compared with the common imbalances in related human cancers ${ }^{[30-32]}$, as summarised in Table 1. In human non-SCC (excluding small cell lung cancers as well), only 7/28 regions (25\%) were affected by copy number variations (CNVs) as in the KLN 205 cell line. Surprisingly, the three other compared human cancer subtypes [human lung cancer (SCC-type), human small cell lung cancer type and head and neck cancer (SCC-type $=$ HNSCC)] revealed CNVs in 12 regions $(\sim 43 \%)$ each that are in the KLN 205 cell line.

\section{DISCUSSION}

The KLN 205 cell line has been applied in around 100 published research studies. While morphologically it seems non-negotiable that KLN 205 in culture appears similar to SCC cells ${ }^{[12-14,24,25]}$, they have been applied as models for lung cancer in general ${ }^{[15-22]}$, metastatic lung cancer cells ${ }^{[26]}$ and even non-small cell lung cancer $^{[23]}$. Surprisingly, they have even worked as a model for tongue cancer ${ }^{[27]}$ and subcutaneous SCC ${ }^{[28]}$.

The present study showed that KLN 205 had an overall stable, approximately tetraploid karyotype with 7782 chromosomes per cell. Thus, this $>40$-year-old cell line still has about the same chromosome number as reported in $1980^{[9]}$. Tetraploidisation was found to obviously have been an early event, possibly already being present in the original tumour or acquired during cell line establishment and early adaptation of the cells to culture conditions ${ }^{[6]}$. Structural chromosomal aberrations are in the lower range of tumour cell lines (see, e.g., the NIH3T3 line ${ }^{[7]}$ ). Thus, the use of KLN 205 as a model for metastatic cancer cells ${ }^{[26]}$ is not justified based on the chromosomal aberrations.

Reviewing the literature, SCCs, independent of their localisation, show relatively few differences in terms of acquired CNVs. It has been stated for HNSCCs that they have a rather uniform CNV pattern, irrespective of whether they derive, e.g., from the larynx, oesophagus or tongue ${ }^{[33]}$. The same was found when comparing HNSCCs and L-SCCs in this study [Table 1]. In addition, it has been shown that the patterns of gains and losses in human lung cancer (SCC-type) and human small cell lung cancer type are strikingly similar as 

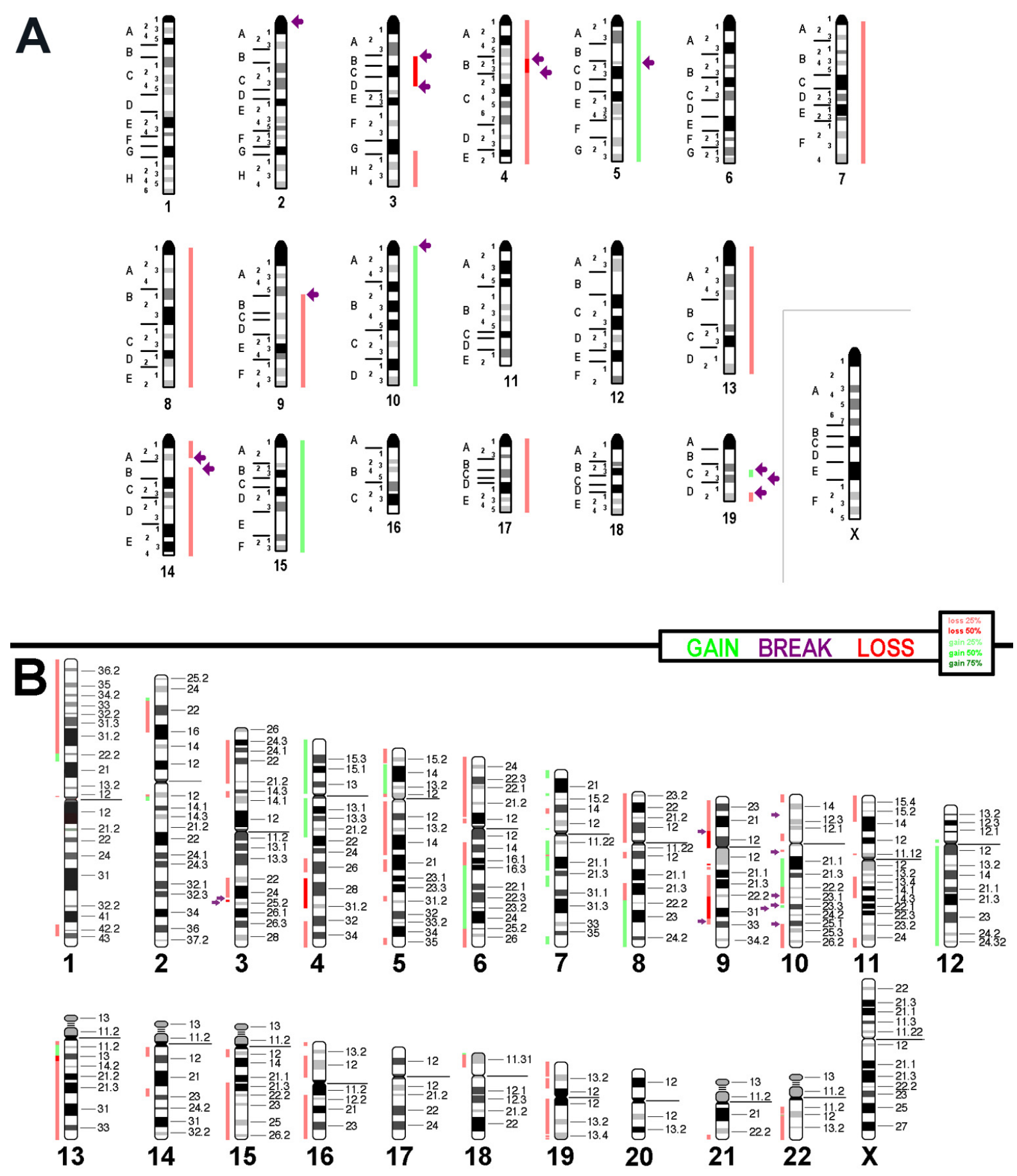

Figure 2. aCGH results and copy number variations detected in the KLN 205 cell line are summarised here with respect to a diploidbasic karyotype. Gains are shown as green bars, losses are shown as red bars and breaks are registered as arrows. (A) The imbalances found in the cell line depicted along a murine chromosome set. (B) The results translated and projected along the human chromosome set.

well $^{[31]}$. Thus, their use as models for SCC cells in general ${ }^{[12-14,24,25]}$ or even for subcutaneous SCC $^{[28]}$ seems to be justifiable. In addition, considering their genetic background, KLN 205 can use as a model for lung cancer in general ${ }^{[15-22]}$, as as well as for even non-small cell lung cancer ${ }^{[23]}$. Their use as a tongue cancer model $^{[27]}$ would only be appropriate if SCC is the cancer type being assessed. 
Table 1. Copy number changes associated with molecular subtypes of human lung cancer (SCC-type), human lung cancer (non-SSCtype and non-small cell lung cancer-type), human small cell lung cancer and head and neck cancer (SCC-type = HNSCC), as shown in $^{[30-32]}$, compared with the copy number variants (CNVs) in the KLN 205 cell line. Concordances with human CNVs are highlighted in bold

\begin{tabular}{|c|c|c|c|c|c|}
\hline $\begin{array}{l}\text { Chromosomal } \\
\text { region }\end{array}$ & $\begin{array}{l}\text { KLN } \\
205\end{array}$ & $\begin{array}{l}\text { Human lung cancer } \\
\text { (SCC) }\end{array}$ & $\begin{array}{l}\text { Human lung cancer (non- } \\
\text { SCC) }\end{array}$ & $\begin{array}{l}\text { Human small cell lung } \\
\text { cancer }\end{array}$ & $\begin{array}{l}\text { Human } \\
\text { HNSCC }\end{array}$ \\
\hline 1pter-p22.3 & Loss & (Loss) & No CNV & Gain & Gain \\
\hline 2p23.1-p16 & Loss & (Gain) & Gain & No CNV & Gain \\
\hline 3p24.3 p14.2 & Loss & Loss & Loss & Loss & Loss \\
\hline $3 q 22-q 24$ & Loss & Gain & Gain & Gain & Gain \\
\hline 4 pter-q21.3 & Gain & Loss & loss & Loss & (Gain) \\
\hline 4q25 qter & Loss & (Loss) & No CNV & (Loss) & Gain \\
\hline 5p15.1-p13.1 & Gain & Gain & Gain & Gain & Gain \\
\hline 5p12 qter & Loss & Loss & Loss & Loss & Loss \\
\hline $6 p$ & Loss & Gain & No CNV & Gain & Gain \\
\hline 6q13-q16.2 & Loss & No CNV & No CNV & Gain & Loss \\
\hline 6q16.3-q25.2 & Gain & No CNV & No CNV & No CNV & (Gain) \\
\hline$\sim 7$ & Gain & Gain & Gain & Gain & Gain \\
\hline $8 p$ & Loss & Loss & Loss & No CNV & Loss \\
\hline 8q22.1-qter & Gain & Gain & Gain & Gain & Gain \\
\hline 9pter-q33 & Loss & Gain & No CNV & No CNV & Loss \\
\hline 10q21.1-q22.2 & Gain & Gain & No CNV & Loss & Gain \\
\hline 10q22.2 qter & Loss & Loss & No CNV & Loss & Gain \\
\hline 11 & Loss & No CNV & No CNV & Gain & Gain \\
\hline 12p12-qter & Gain & Gain & Gain & Gain & Gain \\
\hline 13q12.1-q13 & Gain & Loss & No CNV & Loss & No CNV \\
\hline 13q13-qter & Loss & Loss & No CNV & (Loss) & Gain \\
\hline 15 & Loss & No CNV & No CNV & Loss & Gain \\
\hline$\sim 16 p$ & Loss & No CNV & No CNV & Gain & Gain \\
\hline$\sim 16 q$ & Loss & No CNV & No CNV & Loss & Gain \\
\hline 18p & Loss & Gain & No CNV & (Gain) & No CNV \\
\hline 19 & Loss & Gain & No CNV & Gain & Gain \\
\hline 21q22.3-qter & Loss & No CNV & Gain & No CNV & Gain \\
\hline 22q11.2-qter & Loss & No CNV & No CNV & No CNV & Gain \\
\hline OVERALL & & $12 / 28$ & $7 / 28$ & $12 / 28$ & $12 / 28$ \\
\hline
\end{tabular}

In conclusion, according to the genetic profile of tetraploid KLN 205, this cell line is primarily a model for human SCC. It can also be used to study lung cancer, not restricted to L-SCC, due to the general similarities of CNVs in lung cancer in general. This study may be the starting point for further genetic characterisation of this interesting cell line by other cytogenomic approaches, including second-generation sequencing.

\section{DECLARATIONS}

\section{Acknowledgments}

The technical support of Nadezda Kosyakova (Jena, Germany) is kindly acknowledged. 


\section{Authors' contributions}

Developed the idea for the study and got funded for it: Liehr T

Did the FISH-studies: Azawi S

Performed aCGH studies and did pre-evaluation: Rincic M

Performed the overall data interpretation: Azawi S

Did final paper drafting: Liehr T, Azawi S

All authors agreed on final draft.

\section{Availability of data and materials}

Not applicable.

\section{Financial support and sponsorship}

This work was supported by grant \# 2013.032.1 of the Wilhelm Sander-Stiftung.

\section{Conflicts of interest}

All authors declared that there are no conflicts of interest.

\section{Ethical approval and consent to participate}

According to the ethical committee (medical faculty) and the Animal Experimentation Commission of the Friedrich Schiller University, there are no ethical agreements necessary for studies involving murine tumour cell lines such as KLN 205.

\section{Consent for publication}

Not applicable.

\section{Copyright}

(c) The Author(s) 2021.

\section{REFERENCES}

1. Derman BA, Mileham KF, Bonomi PD, Batus M, Fidler MJ. Treatment of advanced squamous cell carcinoma of the lung: a review. Transl Lung Cancer Res 2015;4:524-32. DOI PubMed PMC

2. Barbone F, Bovenzi M, Cavallieri F, Stanta G. Cigarette smoking and histologic type of lung cancer in men. Chest 1997;112:1474-9. DOI PubMed

3. Hashemi-Sadraei N, Hanna N. Targeting FGFR in squamous cell carcinoma of the lung. Target Oncol 2017;12:741-55. DOI PubMed

4. Nurwidya F, Andarini S, Takahashi F, Syahruddin E, Takahashi K. Implications of insulin-like growth factor 1 receptor activation in lung cancer. Malays J Med Sci 2016;23:9-21. PubMed PMC

5. Tan AC. Targeting the PI3K/Akt/mTOR pathway in non-small cell lung cancer (NSCLC). Thorac Cancer 2020;11:511-8. DOI PubMed PMC

6. Azawi S, Liehr T, Rincic M, Manferrari M. Molecular cytogenomic characterization of the murine breast cancer cell lines C-127I, EMT6/P and TA3 Hauschka. Int J Mol Sci 2020;21:4716. DOI PubMed PMC

7. Leibiger C, Kosyakova N, Mkrtchyan H, Glei M, Trifonov V, Liehr T. First molecular cytogenetic high resolution characterization of the NIH 3T3 cell line by murine multicolor banding. J Histochem Cytochem 2013;61:306-12. DOI PubMed PMC

8. Kaneko T, LePage GA. Growth characteristics and drug responses of a murine lung carcinoma in vitro and in vivo. Cancer Res 1978;38:2084-90. PubMed

9. Kaneko T, LePage GA, Shnitka TK. KLN205--a murine lung carcinoma cell line. In Vitro 1980;16:884-92. DOI PubMed

10. Williams ML, Nettesheim P. Lung colony assay with a squamous cell carcinoma derived from the respiratory tract of mice. $J$ Natl Cancer Inst 1973;51:1513-20. DOI PubMed

11. ATCC. https://www.lgcstandards-atcc.org/products/all/CRL-1453.aspx?geo_country=de\#generalinformation [Last accessed on 11 Jun 2021].

12. Edelblute CM, Guo S, Hornef J, et al. Moderate heat application enhances the efficacy of nanosecond pulse stimulation for the treatment of squamous cell carcinoma. Technol Cancer Res Treat 2018;17:1533033818802305. DOI PubMed PMC

13. Chopra A, O-Sullivan I, Carr J, Kim TS, Cohen EP. T-regulatory cells are relatively deficient in squamous carcinomas undergoing regression in mice immunized with a squamous carcinoma vaccine enriched for immunotherapeutic cells. Cancer Gene Ther 2007;14:573-82. DOI PubMed

14. Hoshitani Y, Ishida H, Otsuki N, Shirakawa T, Gotoh A, Nibu K. Induction of immunological antitumor effects by adenovirus- 
mediated gene transfer of B7-1 in a murine squamous cell carcinoma cell line. Arch Otolaryngol Head Neck Surg 2007;133:270-5. DOI PubMed

15. Mamczur P, Gamian A, Kolodziej J, Dziegiel P, Rakus D. Nuclear localization of aldolase A correlates with cell proliferation. Biochim Biophys Acta 2013;1833:2812-22. DOI PubMed

16. Elbe H, Yigitturk G, Cavusoglu T, Uyanikgil Y, Ozturk F. Apoptotic effects of thymol, a novel monoterpene phenol, on different types of cancer. Bratisl Lek Listy 2020;121:122-8. DOI PubMed

17. Dai CH, Wang Y, Chen P, et al. Suppression of the FA pathway combined with CHK1 inhibitor hypersensitize lung cancer cells to gemcitabine. Sci Rep 2017;7:15031. DOI PubMed PMC

18. Osaki T, Yokoe I, Takahashi K, et al. Metformin enhances the cytotoxicity of 5-aminolevulinic acid-mediated photodynamic therapy in vitro. Oncol Lett 2017;14:1049-53. DOI PubMed PMC

19. Kataoka K, Huh N. A novel $\beta 1,3-\mathrm{N}$-acetylglucosaminyltransferase involved in invasion of cancer cells as assayed in vitro. Biochem Biophys Res Commun 2002;294:843-8. DOI PubMed

20. Roberts K, Kilshaw PJ. The mucosal T cell integrin alpha M290 beta 7 recognizes a ligand on mucosal epithelial cell lines. Eur J Immunol 1993;23:1630-5. DOI PubMed

21. Couch MJ, Pauli BU, Weinstein RS, Coon JS. Induction of reversible changes in cell-surface glycoconjugates and lung colonization potential by 13-cis retinoic acid. J Cell Biochem 1988;37:213-23. DOI PubMed

22. Rim KT, Kim SJ. Quantitative analysis of exosomes from murine lung cancer cells by flow cytometry. J Cancer Prev 2016;21:194200. DOI PubMed PMC

23. Boffa DJ, Luan F, Thomas D, et al. Rapamycin inhibits the growth and metastatic progression of non-small cell lung cancer. Clin Cancer Res 2004;10:293-300. DOI PubMed

24. Akimoto J, Nakayama M, Takagi S, Okano T. Improved in vivo subcutaneous tumor generation by cancer cell sheet transplantation. Anticancer Res 2018;38:671-6. DOI PubMed

25. Ahmad I, Longenecker M, Samuel J, Allen TM. Antibody-targeted delivery of doxorubicin entrapped in sterically stabilized liposomes can eradicate lung cancer in mice. Cancer Res 1993;53:1484-8. PubMed

26. Zhu D, Cheng CF, Pauli BU. Blocking of lung endothelial cell adhesion molecule-1 (Lu-ECAM-1) inhibits murine melanoma lung metastasis. J Clin Invest 1992;89:1718-24. DOI PubMed PMC

27. Li X, Bukawa H, Hirota M, Tsuyuki Y, Omura S, Fujita K. Novel OK-432-conjugated tumor vaccines induce tumor-specific immunity against murine tongue cancer. $J$ Dent Res 2003;82:636-40. DOI PubMed

28. Manshian BB, Jimenez J, Himmelreich U, Soenen SJ. Presence of an immune system increases anti-tumor effect of Ag nanoparticle treated mice. Adv Healthc Mater 2017;6:1601099. DOI PubMed

29. Kubicova E, Trifonov V, Borovecki F, et al. First molecular cytogenetic characterization of murine malignant mesothelioma cell line AE17 and in silico translation to the human genome. CBIO 2017;12:11-8. DOI

30. Lo FY, Chang JW, Chang IS, et al. The database of chromosome imbalance regions and genes resided in lung cancer from Asian and Caucasian identified by array-comparative genomic hybridization. BMC Cancer 2012;12:235. DOI PubMed PMC

31. Petersen I, Petersen S. Towards a genetic-based classification of human lung cancer. Anal Cell Pathol 2001;22:111-21. DOI PubMed PMC

32. Wolff E, Girod S, Liehr T, et al. Oral squamous cell carcinomas are characterized by a rather uniform pattern of genomic imbalances detected by comparative genomic hybridisation. Oral Oncology 1998;34:186-90. DOI PubMed 